\title{
ANALISIS RISIKO USAHATANI BUNGA KRISAN POTONG (Chrysanthenum indicum L) (Studi kasus di PT Alam Indah Bunga Nusantara)
}

\author{
Jannet Aszury Astaningrum dan Endah Djuwendah \\ Program Studi Agribisnis, Fakultas Pertanian, Universitas Padjadjaran \\ Joe.aszury@gmail.com \\ Program Studi Agribisnis, Fakultas Pertanian, Universitas Padjadjaran \\ endah_djuwendah @unpad.ac.id
}

\begin{abstract}
Horticulture is one of the sub-sectors in agriculture that have the potential to be developed asit has a high economic value. One of the featured plants that have good prospects for development in Indonesia is the chrysanthemum. In the process of cultivation of chrysanthemums, required skills and intensive treatment of the chrysanthemum. therefore at high risk of cultivation process. PT Alam Indah Bunga Nusantara is one of the companies engaged in the agribusiness plants located in West Java. The purpose of this research was to determine factors that will influence the risk in chrysanthemum cut flower farm, to determine the extent of risk management which conducted in PT Alam Indah Bunga Nusantara, and know the strategies to improve risk conducted in PT Alam Indah Bunga Nusantara. The study design used was a qualitative design using FMEA analysis (Failure Mode and Effect Analysis). Engineering research is to study the case. The result was the risks faced in PT Alam Indah Bunga Nusantara is the weather and the climate change problem that occurs is uncertain. In addition, pests and diseases is also a risk that must be covered by the company. This can lead to a lot of things that could detrimental to the company in the business of chrysanthemums. In addition to natural factors, uncertainty in consumer tastes is a cause of risk faced by PT Alam Indah Bunga Nusantara. The new effort conducted by PT Alam Indah Bunga Nusantara in improving the quality of human resources in the company is to conduct junior secondary education program. The strategy must do for PT Alam Indah Bunga Nusantara for improve the risk is repair the greenhouse to be more optimized than previous, adding a thermostat in the greenhouse.
\end{abstract}

Keywords: Risk Analysis, Chrysanthemum indicum L, Failure Mode and Effect Analysis

\section{PENDAHULUAN}

Krisan atau Chrysanthenum merupakan salah satu jenis tanaman hias yang telah lama dikenal dan banyak disukai masyarakat serta mempunyai nilai ekonomi yang tinggi. Bunga krisan juga memiliki kesegaran yang relatif lama dan mudah dirangkai. Krisan merupakan salah satu jenis bunga potong penting. Pada perdagangan tanaman hias dunia, bunga krisan merupakan salah satu bunga yang banyak diminati oleh beberapa negara Asia seperti Jepang, Singapore dan Hongkong, serta Eropa seperti Jerman, Perancis dan Inggris.
PT Alam Indah Bunga Nusantara merupakan salah satu perusahaan agribisnis yang bergerak di bidang tanaman hias yang terletak di Jawa Barat. Tanaman yang paling unggul dihasilkan perusahaan adalah krisan. Perusahaan ini mampu meningkatkan produksinya untuk memenuhi kebutuhan bunga potong (khususnya bunga krisan potong) dari dalam negeri maupun luar negeri. Sampai saat ini ada lebih dari 33 varietasbunga krisan yang diproduksi oleh PT Alam Indah Bunga Nusantara. 
PT Alam Indah Bunga Nusantara membuat motherstock sendiri, agar dapat menambah volume produksi dengan tetap mempertahankan kualitas bunga tersebut.PT Alam Indah Bunga Nusantara juga mempunyai kesulitan yang dihadapi. Seperti permintaan pasar lokal yang fluktuatif karena masyarakat yang belum menjadikan bunga sebagai suatu kebutuhan bagi mereka. Usaha bunga krisan memiliki risiko dalam produksinya. Risiko yang dihadapi dalam usaha krisan di PT Alam Indah Bunga Nusantara antara lain risiko teknis (produksi) dan risiko pasar. Sumber risiko teknis dalam produksi bunga krisan antara lain kondisi cuaca yang tidak pasti, serangan hama penyakit yang sulit diprediksi sebelumnya serta efisiensi penggunaan input. Selain risiko produksi krisan juga dihadapkan pada risiko harga. Sumber risiko harga antara lainfluktuasi harga bibit, pupuk, obat-obatan dan harga jual tanaman hias di pasaran. Adanya risiko produksi dan risiko harga tersebut akan mempengaruhi keberhasilan dan keuntungan yang diterima usaha krisan. Cara memperbaiki risiko tersebut yang bertujuan menekan dampak risiko dalam usaha krisan menjadi suatu hal yang menarik untuk dikaji. Oleh karena itu penelitian mengenai risiko usahatani bunga krisan penting untuk dilakukan. Penelitian dilakukan untuk mengetahui sumber sumber risiko yang dihadapi PT Alam Indah Bunga Nusantara dalam usahatani bunga krisan, pengelolaan risiko yang sudah dilakukan PT Alam Indah Bunga Nusantara dan strategi untuk memperbaiki risiko di PT Alam Indah Bunga Nusantara.

\section{METODE PENELITIAN}

Desain yang digunakan dalam penelitian ini adalah kualitatif. Untuk mengidentifikasi sumber-sumber risiko dan menganalisis manajemen risiko usahatani bunga krisan yang dilakukan PT Alam Indah Bunga Nusantara menggunakan analisis FMEA (Failure Mode and Effect Analysis), yaitu dengan cara mengidentifikasi risiko, mengukur risiko, dan membuat prioritas risiko tersebut.Teknik penelitian yang dilakukan adalah studi kasus (case study). Studi kasus yaitu menggambarkan secara mendalam mengenai risiko dalam usahatani bunga krisan serta strategi yang dilakukan untuk memperbaiki risiko.Failure Mode and Effect Analysis merupakanmetode sistematis yang mengidentifikasi dan mencegah masalah sistem, produk, dan proses sebelum terjadi. FMEA difokuskan untuk mencegah masalah, meningkatkan keamanan, dan meningkatkan kepuasan pelanggan. Idealnya, FMEA dilakukan untuk desain produk, akan tetapi bisa juga digunakan untuk proses. Metodologi pada penelitian ini mengacu pada suatu framework (kerangka kerja) karena konsepmanajemen risiko usahatani yang luas. Kerangka kerja ini berisi langkah-langkah dan landasan melakukan identifikasi, analisa, evaluasi risiko dan perancangan strategi dalam usahatani.

Tahapan analisa dalam penelitian ini adalah pengumpulan data melalui wawancara, tahap selanjutnya menganalisis data yang terkumpul dengan menggunakan Failure Mode and Effect Analysis(FMEA), sebagai teknik mengidentifikasi dan menilai risiko dalam usahatani bunga krisan, yaitu dengan mengelompokkan sumber risiko dengan menggunakan Risk Priority Number dan RiskScore Value. Tujuan dari FMEA adalah untukmengetahui dampak dari kegagalan dalam sistem operasi kemudian mengklasifikasikan setiap kegagalan fungsi dalam tingkatan kepentingannya.

\section{HASIL DAN PEMBAHASAN}

\section{Identifikasi Risiko PT Alam Indah Bunga Nusantara}

Risiko usahatani menyangkut seluruh kegiatan proses produksi yang dilakukan PT Alam Indah Bunga Nusantara mulai dari proses pembibitan, persiapan lahan, pemeliharaan, pemanenan, hingga pasca panen. Selain itu faktor hama dan penyakit, cuaca dan iklim, bencana alam, tenaga kerja serta teknologi juga 
termasuk didalamnya. Apabila hal tersebut terjadi maka akan mempengaruhi produksi krisan di PT Alam Indah Bunga Nusantara baik secara kuantitas maupun kualitas dari krisan itu sendiri.

Kualitas bibit tergantung masing masing varietas. Bibit akan mengalami penurunan kualitas dalam waktu tertentu. Semakin lama umur bibit maka kualitas dari bibit tersebut semakin rendah. Misalnya tanaman menjadi kerdil. Kendala yang sering dihadapi PT Alam Indah Bunga Nusantara adalah ketersediaan bibit yang sering terlambat karena berasal dari Belanda.

Masalah yang dihadapi dibagian produksi adalah pengaturan pinching sulit dilakukan. Karena permintaan yang fluktuatif untuk warna tertentu setiap minggunya. Misalnya kebutuhan krisan jenis Yellow Fiji pada minggu pertama hanya 200buah, akan tetapi pinching yang dilakukan lebih dari itu, sehingga kelebihan stek terbuang. Hal tersebut bisa diatasi dengan cara disimpan, akan tetapi akan berakibat terhadap penurunan kualitas dari krisan itu sendiri.Masalah yang paling mempengaruhi pada proses produksi adalah faktor alam, Cuaca dan iklim serta bencana alam yang tidak bisa diprediksi sebelumnya. Akibat dari faktor tersebut panen menjadi lebih cepat atau panen menjadi terlambat dari waktu umur tanaman yang sudah diperkirakan. Misalnya karena terlalu panas maka krisan akan cepat berbunga, sehingga panen cepat dilakukan. Sebaliknya jika kondisi lingkungan lembab, krisan akan lama berbunga. Sementara pola tanam sudah disesuaikan dengan umur krisan itu sendiri sehingga dapat dipanen tepat waktu.

Hama dan penyakit sangat mempengaruhi produksi krisan. Kondisi lembab, penyakit yang sering menyerang krisan adalah busuk batang dan bakteri. Sebaliknya kondisi kemarau hama trip, mait, dan karat menyerang. Apabila tidak segera diatasi maka dapat berdampak buruk pada krisan. Kondisi greenhouse berpegaruh terhadap keadaan bunga krisan pada proses produksi. Standar suhu dalam greenhouse antara $17 \square \mathrm{C}-30 \square \mathrm{C}$ untuk proses penanaman dan pembungaan dibutuhkan suhu $16 \square \mathrm{C}-18 \square \mathrm{C}$. Standar untuk kelembaban dalam greenhouse dibutuhkan $70 \%-80 \%$

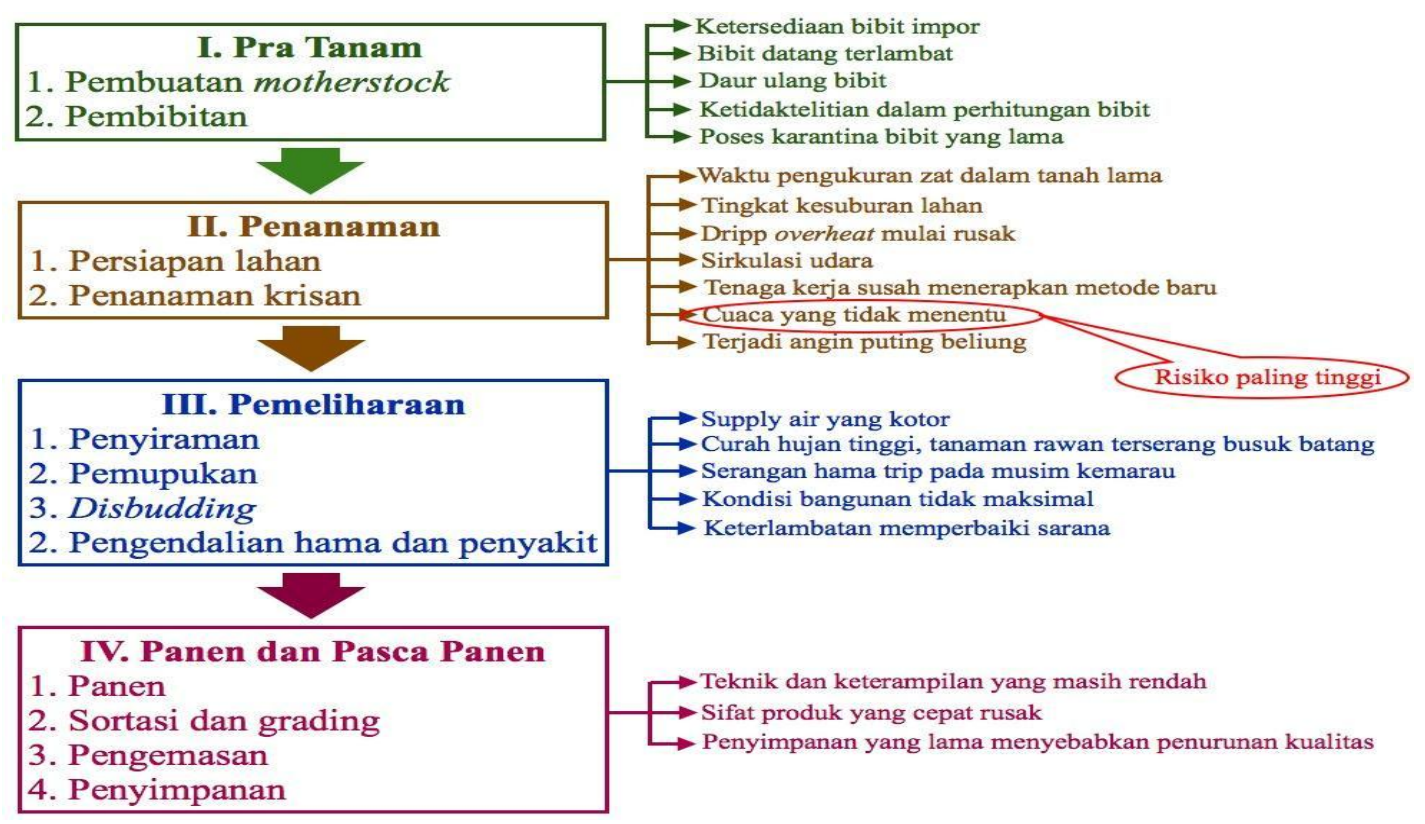

Gambar 1. Alur Proses Produksi dan Sumber Risiko 
Bangunan greenhouse banyak yang mulai rusak karena terbawa angin sehingga membutuhkan proses untuk memperbaiki. Perbaikan yang dilakukan cukup lama karena harus menunggu tenaga kerja terlebih dahulu. Sementara untuk mendapatkan alat dan bahan untuk memperbaiki bangunan tidak mudah. Adanya masalah pada bangunan greenhouse sangat berpengaruh terhadap produksi krisan. Misalnya, terdapat lubang yang menyebabkan greenhouse tersebut terbuka sehingga pertumbuhan krisan terganggu dan hama akan mudah menyerang krisan.

Fan (sirkulasi udara) terdapat di seluruh greenhouse. Alat tersebut didatangkan dari Belanda sehingga apabila terjadi kerusakan maka akan sulit untuk diperbaiki. Kondisi Fan di PT Alam Indah Bunga Nusantara sudah mulai rusak, dilihat dari putarannya yang semakin berkurang, mengakibatkan suhu didalam greenhouse menjadi naik dan berpengaruh terhadap krisan itu sendiri.

Air yang digunakan untuk irigasi di PT ALam Indah Bunga Nusantara berasal dari sumber mata air pengunungan sekitar. Masalah yang dihadapi oleh perusahaan adalah kondisi air yang didapat tidaklah bagus, terkadang banyak terdapat benda lain seperti gumpalan tanah yang ada di air tersebut. Sementara itu untuk proses penyiraman dilakukan menggunakan drip irigasi dan overhead. Kondisi alat tersebut sudah banyak yang tersumbat dan rusak karena masuknya benda benda asing kedalam saluran tersebut sehingga penyiraman tidak merata dan mengakibatkan tanaman menjadi bergelombang.

Keterbatasan teknologi juga merupakan masalah yang harus dihadapi PT Alam Indah Bunga Nusantara. Seperti belum adanya alat yang bisa melihat kondisi dan kandungan tanah dengan cepat dan tepat dan alat pengatur suhu yang ada didalam greenhouse. Acuan tingkat kesuburan tanah hanya dilihat dari hasil produksi sebelumnya dilahan tersebut.

Keterbatasan pendidikan pada tenaga kerja juga menjadi kendala pada proses produksi.
Mayoritas pendidikan tenaga kerja yang bekerja di departemen produksi hanya tamatan SD. Hal tersebut tentu saja sangat berpengaruh. Pada proses produksi tidak hanya membutuhkan tenaga tetapi juga pemikiran dan ketelitian. Misalnya untuk memasang label tanaman pada setiap blok tanaman krisan sering terjadi kesalahan dalam melabelkan nama, sehingga menimbulkan kekeliruan dalam pencacatan data. Departemen marketing menangani bagian pasca panen hingga pengiriman krisan kepada konsumen. Banyak kendala yang dihadapi di bagian marketing sehingga berpengaruh terhadap proses produksi. Permintaan konsumen yang bermacam-macam mengakibatkan sulitnya memprediksi varietas krisan yang laku dipasaran. Sementara itu proses produksi krisan membutuhkan waktu yang cukup lama.

Masalah yang dihadapi bagian keuangan adalah ketika banyak para pembeli yang tidak membayarkan hutang mereka sehingga kreditmacet. Hal tersebut berdampak pada proses produksi karena akan susah untuk membeli bahan yang dibutuhkan untuk proses pemeliharaan seperti pupuk dan pestisida. Untuk menutupi kekurangan biaya produksi selanjutnya, dana cadangan berasal dari pinjaman bank dan dari pemegang saham. Perusahaan sulit untuk mengontrol pembayaran karena tempat konsumen yang berada diluar pulau.Berdasarkan pada grafik pareto yang telah dibuat nilai kritis untuk Risk Priority Number (RPN) adalah 500 dan nilai kritis untuk Risk Score Value (RSV) adalah 60. Maka dibuat diagram pencar (scatter plot) untuk Risk Priority Number (RPN) dan Risk Score Value (RSV) dengan tujuan untuk menemukan persimpangan kedua nilai kritis. Risiko dengan nilai tertinggi dapat segera diambil pencegahannya terlebih dahulu.

Departemen marketing menangani bagian pasca panen hingga pengiriman krisan kepada konsumen. Banyak kendala yang dihadapi di bagian marketing sehingga berpengaruh terhadap proses produksi. Permintaan konsumen yang bermacam-macam mengakibatkan sulitnya 
memprediksi varietas krisan yang laku dipasaran. Sementara itu proses produksi krisan membutuhkan waktu yang cukup lama. Masalah yang dihadapi bagian keuangan adalah ketika banyak para pembeli yang tidak membayarkan hutang mereka sehingga kreditmacet. Hal tersebut berdampak pada proses produksi karena akan susah untuk membeli bahan yang dibutuhkan untuk proses pemeliharaan seperti pupuk dan pestisida. Untuk menutupi kekurangan biaya produksi selanjutnya, dana cadangan berasal dari pinjaman bank dan dari pemegang saham. Perusahaan sulit untuk mengontrol pembayaran karena tempat konsumen yang berada diluar pulau.Berdasarkan pada grafik pareto yang telah dibuat nilai kritis untuk Risk Priority Number (RPN) adalah 500 dan nilai kritis untuk Risk Score Value (RSV) adalah 60. Maka dibuat diagram pencar (scatter plot) untuk Risk Priority Number (RPN) dan Risk Score Value (RSV) dengan tujuan untuk menemukan persimpangan kedua nilai kritis. Risiko dengan nilai tertinggi dapat segera diambil pencegahannya terlebih dahulu.

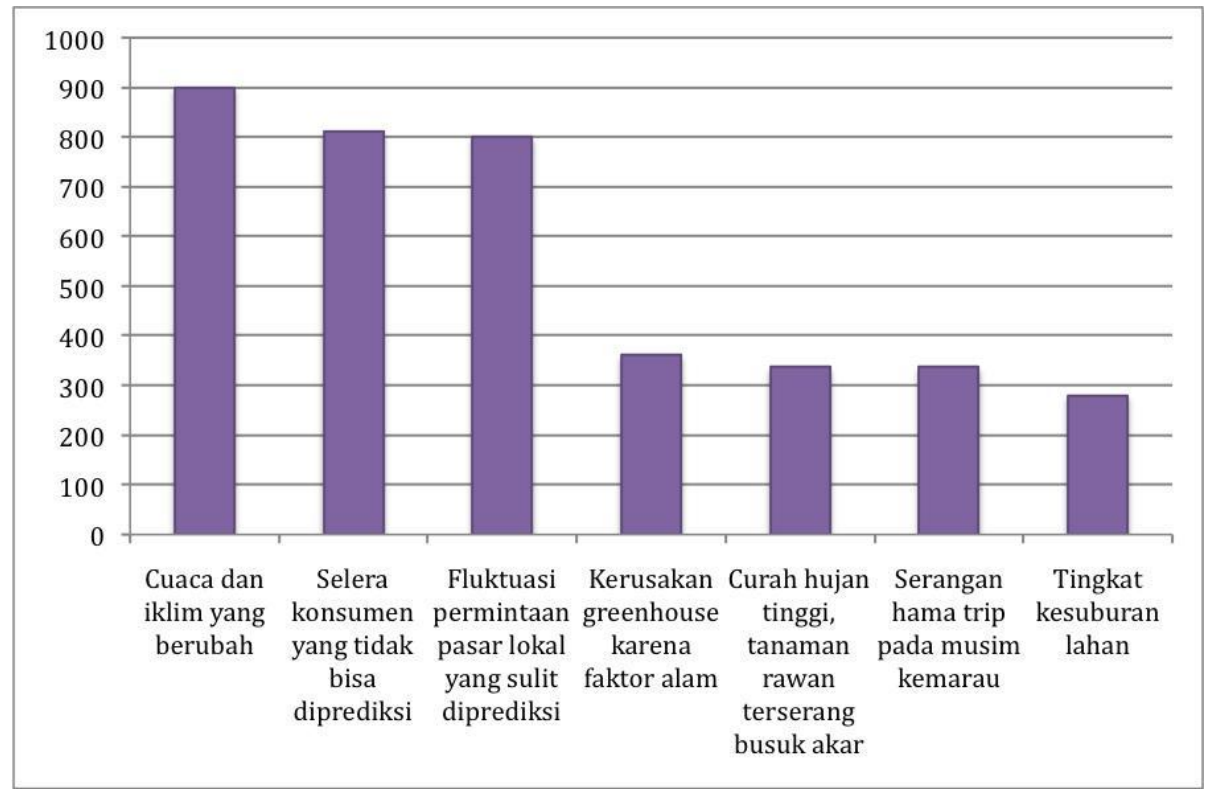

Gambar 2. Grafik Pareto Risk Priority Number(RPN)

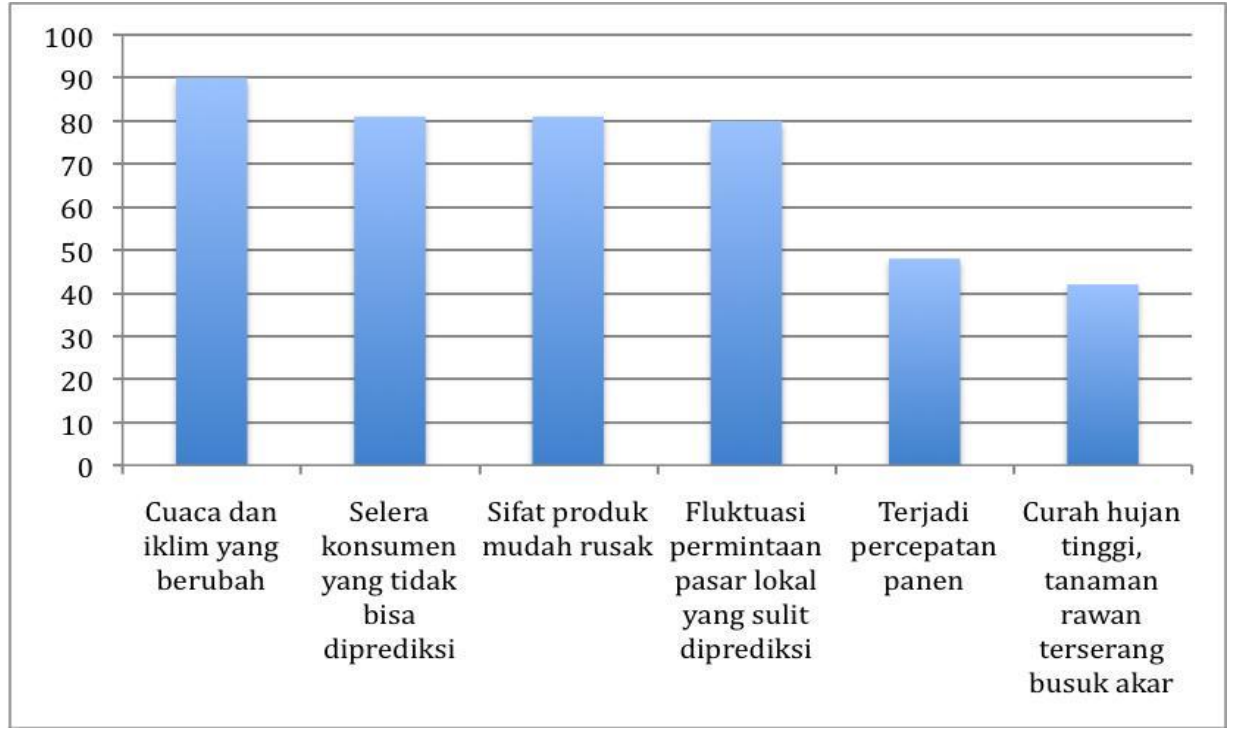

Gambar 3. Grafik Pareto Risk Score Value (RSV) 
6|PASPALUM VOL IIINo. 1 Maret 2015

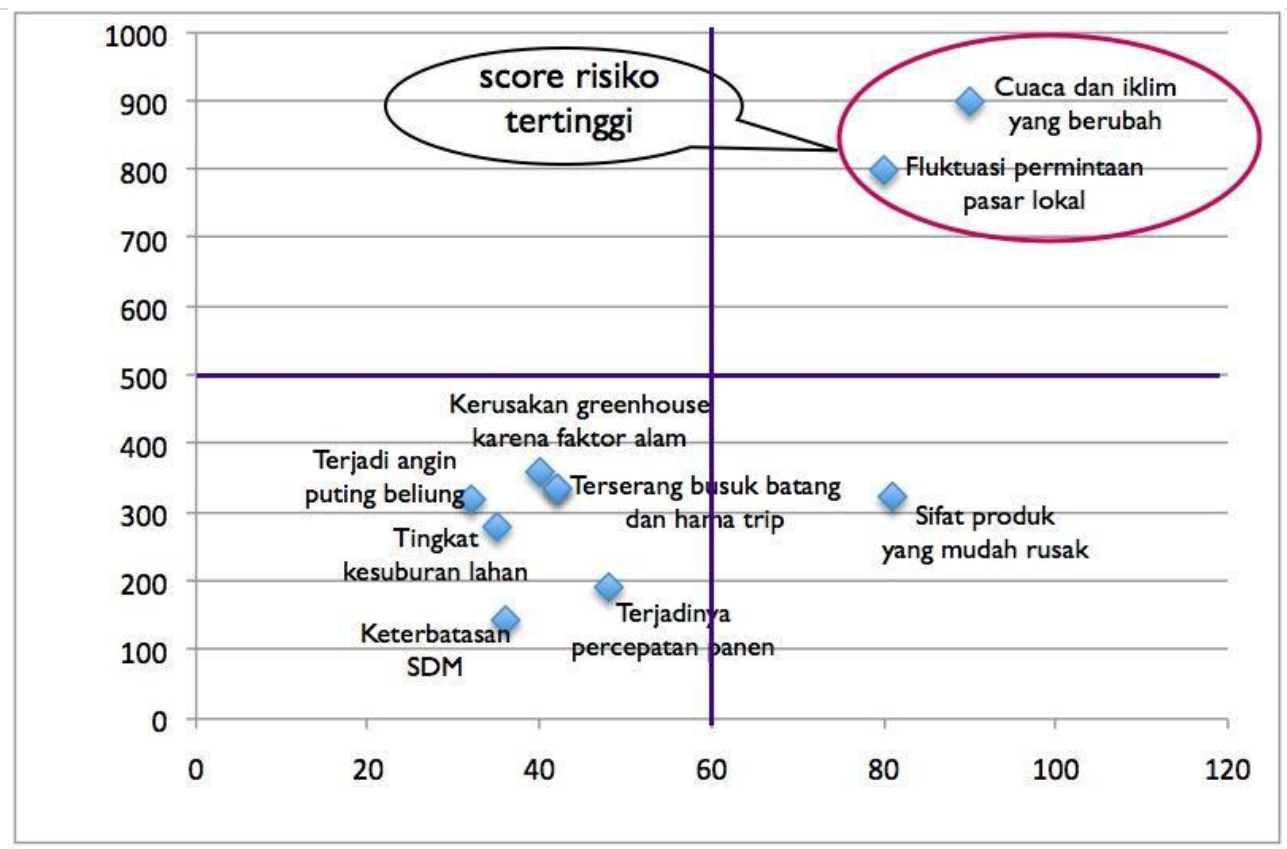

Gambar 4. Pengelompokkan Risiko BerdasarkanRPN dan RSV

Gambar 4 menunjukkan bahwa nilai kritis dariRisk Priority Number (RPN) dan Risk Score Value (RSV) membagi diagram menjadi empat bagian. Daerah kanan bagian atas merupakan risiko yang paling mendesak karena mempunyai nilai RiskPriority Number (RPN) dan Risk Score Value (RSV)tinggi, yang harus segera ditangani secepatnya. Terdapat tiga risiko yang berada didaerah tersebut. yaitu cuaca dan iklim yang berubah, fluktuasi permintaan pasar dan selera konsumen yang sulit diprediksi. Risiko tertinggi yang terdeteksi menjadi pehatian utama di PT Alam Indah Bunga Nusantara sehingga strategi risiko diperlukan agar tidak mengganggu aktivitas lain yang berada di PT Alam Indah Bunga Nusantara.

\section{Strategi Mengatasi Risiko PT Alam Indah} Bunga Nusantara yang sudah dilakukan

Berdasarkan penggunaan metode Failure Modeand Effect Analysis (FMEA), diketahui bahwa risikoyang paling tinggi berdasarkan Risk PriorityNumber (RPN) dan Risk Score Value (RSV) adalahcuaca dan iklim yang tidak pasti. Faktor yang menyebabkan hal tersebut terjadi karena kerusakan greenhouse yang menyebabkan cuaca dan iklim menjadi sangat berpengaruh dalam proses produksi. Hal tersebut membuktikan bahwa risiko yang memiliki nilai yang tinggi dan harus diproritaskan terlebih dahulu adalah cuaca dan iklim.

Upaya untuk menekan fluktuasi permintaan konsumen sudah dilakukan PT Alam Indah Bunga Nusantara yaitu dengan cara membuat perencanaan produksi Jumlah tanaman yang akan diproduksi merujuk kepada permintaan pasar dan disesuaikan dengan ketersediaan bibit yang ada dimotherstock dan nursery. Oleh karena itu PTAlam Indah Bunga Nusantara membuat perencanaan produksi untuk menghindari kelebihan atau kekurangan produksi nantinya dengan cara mengatur komposisi jenis bunga dan jumlahnya yang akan ditanam. Serangan hama dan penyakit tanaman selalu ada pada setiap proses produksi bunga krisan. Upaya yang sudah dilakukan PT Alam Indah Bunga Nusantara dalam mencegah penyebaran hama dan penyakit adalah dengan melakukan penyemprotan untuk tindakan pencegahan. Tanaman diamati terlebih dahulu, apabila terjadi penyebaran hama maka langsung dilakukan tindakan tersebut. 
Keterbatasan sumber daya manusia juga merupakan risiko yang dihadapi PT Alam Indah Bunga Nusantara karena sumber tenaga kerja berasal dari daerah dekat perusahaan yang ratarata berpendidikan tamat sekolah dasar. Kegiatan yang sudah dilakukan oleh PT Alam Indah Bunga Nusantara untuk menangani risiko tersebut adalah dengan cara menyediakan fasilitas untuk meningkatkan pendidikan pada ketua kelompok kerja yang awalnya berpendidikan sekolah dasar, diadakan pendidikan paket B yang disediakan di perusahaan setingkat dengan sekolah menengah pertama pada akhirnya. Perusahaan berkerja sama dengan pihak dinas pendidikan untuk menyelenggarakan proses belajar mengajar.

Pelatihan kepemimpinan dilakukan untuk para koordinator unit kerja yang bertanggung jawab setiap blok serta unit kerja. Kegiatan ini diselenggarakan dengan tujuan untuk meningkatkan kapabilitas karyawan dalam aspek leadership dan manajerial.

3. Opsi Strategi PT Alam Indah Bunga Nusantara ke Depan

PT Alam Indah Bunga Nusantara mempunyai berbagai macam risiko yang dihadapi. Salah satunya menghadapi fluktuasi cuaca dan iklim yang berubah-ubah. Strategi yang dipakai untuk mengatasi risiko-risiko di PT Alam Indah Bunga Nusantara dilakukan dengan cara strategi mitigasi, yaitu mecegah atau meminamilisir risiko yang terjadi di PT Alam Indah Bunga Nusantara. Guna mengatasi risiko dari cuaca dan iklim yang sulit diprediksi dapat dicegah dengan memperkuat kondisi bangunan greenhouse.Memperbaiki bahan bangunan greenhouse yang rusak seperti plastik UV yang sudah berlubang, memperbaiki fan yang rusak, memasang alat pengatur suhu agar dapat mengetahui suhu dan kelembaban dalam greenhouse tersebut sehingga dapat dilakukan tindakan pencegahan. PT Alam Indah Bunga Nusantara juga dapat bekerja sama dengan pihak luar dalam mengetahui kondisi cuaca dalam waktu dekat. Sehingga perusahaan dapat mengatur strategi dalam memproduksi krisan.

Upaya yang perlu dilakukan oleh bidang marketing adalah meningkatkankomunikasi dengan konsumen, dengan cara lebih menanyakan kebutuhan konsumen akan krisan sehingga bidang marketing bisa meningkatkan prediksi, perencanaan produksi yang lebih akurat.

Upaya memperkecil risiko keuangan yang dilakukan oleh PT Alam Indah Bunga Nusantara dengan cara memberlakukan sistem pembayaran di awal. Jadi konsumen yang akan membeli bunga krisan di PT Alam Indah Bunga Nusantara wajib membayar uang muka sebelum bunga dikirim dan sisanya di bayarkan pada saat bunga sudah sampai ditangan konsumen.

Diversifikasi merupakan salah satu usaha penganekaragaman produk untuk menghindari ketergantungan pada salah satu hasil pertanian. Diversifikasi dilakukan dengan memperbanyak jenis tanaman yang ditanam pada satu lahan. Diversifikasi bisa dilakukan di PT Alam Indah Bunga Nusantara, yaitu dengan cara menambahkan tanaman daun potong. Daun potong dibutuhkan sebagai bahan dekorasi. Diversifikasi dapat mengurangi risiko usahatani krisan di PT Alam Indah Bunga Nusantara, tetapi dengan melakukan hal tersebut tidak membuat risiko menjadi nol. Artinya meskipun perusahaan telah melakukan diversifikasi, PT Alam Indah Bunga Nusantara akan tetap menghadapi risiko produksi, akan tetapi tingkat risikonya lebih kecil dibandingkan tidak melakukan diversifikasi. 


\section{KESIMPULAN DAN SARAN}

Sumber-sumber risiko usahatani yang dihadapi PT Alam Indah Bunga Nusantara adalah perubahan cuaca dan iklim yang tidak dapat diprediksi, fluktuasi permintaan pasar lokal, kerusakan greenhouse karena faktor alam, sifat produkyang mudah rusak, tingkat kesuburan lahan, keterbatasan sumber daya manusia.

Pengelolaan risiko yang sudah dilakukan PT Alam Indah Bunga Nusantara adalah dengan cara preventif, yaitu mengembangkan sumber daya manusia. Mengadakan peningkatan pendidikan dari sekolah dasar menjadi setara dengan sekolah menengah pertama. Tindakan tersebut dilakukan untuk memperkecil terjadinya ketidaktelitian dalam perhitungan bibit dan untuk meningkatkan kreatifitas tenaga kerja tersebut. PT Alam Indah Bunga Nusantara membuat perencanaan produksi agar penanaman jumlah varietas krisan dapat disesuaikan dengan bagian produksi dan nursery. Penyemprotan pestisida dilakukan lebih awal dengan tujuan dapat menekan dan meminimalisir pertumbuhan hama dan penyakit.

Strategi yang dapat dilakukan PT Alam Indah Bunga Nusantara dalam proses produksi adalah dengan memperbaiki kondisi greenhouse sehingga penggunaannya dapat lebih optimal. Guna memperkecil sumber risiko keuangan dapat dilakukan dengan cara penyitaan aset dan melakukan sistem pembayaran di awal.

Sebagai saran, Untuk meminimalkan risiko yang dihadapi PT Alam Indah Bunga Nusantara dapat lebih memfokuskan perhatian pada proses produksi bunga krisan, yaitu perusahaan lebih mengoptimalkan lagi greenhouse dengan cara melakukan perbaikan dan penambahan fasilitas yang terdapat dalam greenhouse tersebut, seperti penambahan alat ukur dan pengatur suhu. PT
Alam Indah Bunga Nusantara bisa lebih meningkatkan kerja sama dengan perusahaan luar negeri dibidang perkiraan cuaca, agar dapatmengetahui kondisi cuaca yang lebih akurat setiap harinya.

\section{UCAPAN TERIMAKASIH}

Terimakasih kepada semua pihak yang telah membantu dalam penelitian ini, terutama kepada Ibu Endah Djuwendah, SP., MSi. selaku dosen pembimbing dan PT Alam Indah Bunga Nusantara.

\section{DAFTAR PUSTAKA}

Adiyoga, W. dan T. A. Soetiarso. 1997. Keunggulan Komparatif dan Insentif Ekonomi Usahatani Bawang Merah. Jurnal Hortikultura, 7 (1): 614-621.

Carbone, T. A. And D. D Tippett. 2004. ProjectRisk Management using the project risk FMEA."Engineering Management Journal", vol. 16, no. 4, hal. 28-35.

Darmawi H. 2006. Manajemen Risiko. Jakarta: PT Bumi Aksara.

Fahmi, Irham. 2010. Manajemen Risiko: Teori,Kasus, dan Solusi. Bandung: Alfabeta.

Kountur R. 2008. Mudah MemahamiManajemen Risiko Perusahaan. Jakarta: PPM.P2M Departemen Teknik Mesin. 2009. In House Training Failure Mode Effect Analysis. Fakultas Teknik. Universitas Indonesia.

Robinson, L.J and P.J Barry. 1987. The Competitive Firm's Response to Risk. London:Macmillan Publisher.

Zeng, Sai X., Tam, Chun M., And Vivian, W. Y. Tam. 2010. Integrating Safety, Environmental andQuality Risks for Project Management Using a FMEA Method. "Economics of EngineeringDecisions", 21 (1), hal. 44-52

Penulis Petama adalah mahasiswa program studi Agribisnis Fakultas Pertanian Unpad dan Penulis Kedua adalah Staf Pengajat di Fakultas Pertanian Unpad 